\title{
Natural leather car upholstery - characteristics and sewing challenges
}

\section{Ph. D. Beti Rogina-Car, Ph. D. Stana Kovačević, Prof. University of Zagreb Faculty of Textile Technology}

E-mail: beti.rogina-car@ttf.hr
Professional Paper

UDK: 675.14.017:629.3.04

\begin{abstract}
This paper gives an overview of materials and specifics in production of upholstery for vehicles. Special attention has been paid to natural leather as one of the most luxurious materials for the manufacture of car interior upholstery materials. Its properties, advantages and disadvantages are compared with textile materials. The quality of suitable seams is one of the most challenging tasks in making upholstery. In this paper, special emphasis is placed on cutting and sewing natural leather used for making car interior upholstery. Natural leather is a specific natural material that gives a touch of luxury to car seats and interiors. Durability, high price and lower market offer of leather lead to its restricted use for car upholstery compared to textile materials; however, these reasons in particular make it extremely desirable at the same time. According to previous research, cutting and sewing of leather car upholstery require greater attention also when choosing the appropriate leather, sewing machine, thread, needle and seam type, which will give satisfactory properties of the car upholstery in all segments. The purpose of this paper is to contribute to professional knowledge and specifics related to natural leather, its use for car seats and the proper quality of the sewn seam.
\end{abstract}

\section{Keywords}

natural leather, car upholstery, properties of natural leather, sewn seam.

\section{Introduction}

Materials used to make car interior upholstery for vehicles are made of different materials by employing various technological processes. Natural leather is one of the most expensive, but also the most desirable materials used for seat upholstery and car interior. With its exceptionally beautiful and luxurious appearance, it attracts the customer and contributes to their decision to buy the car, Fig. 1.

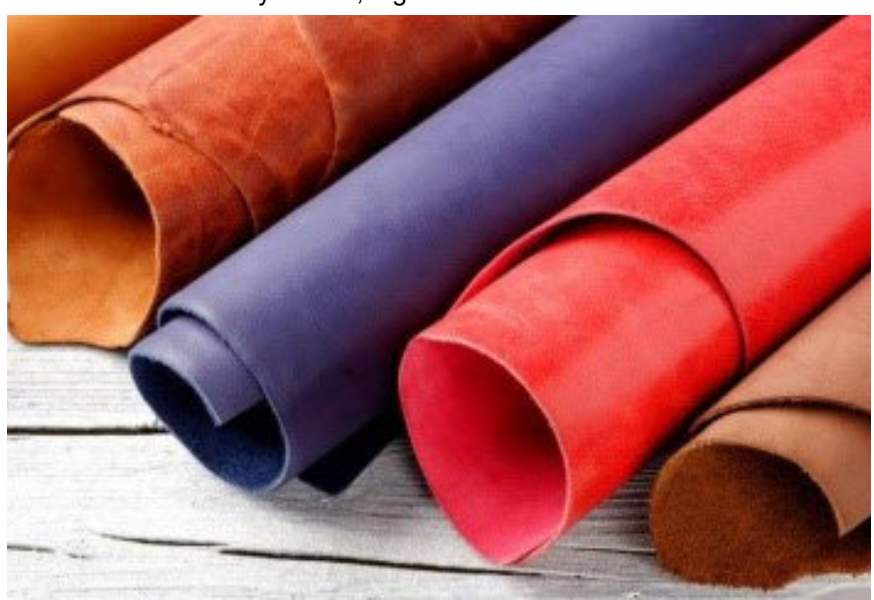

Figure 1. Natural leather [1]

Extremely strong natural animal skins of bulls, cows, calves, horses, pigs, goats and sheep are used to make leather car upholstery. Leather is a very durable and resistant material, but at the same time elastic and breathable. Positive properties of natural leather are high strength, elasticity, abrasion resistance, good air permeability, softness and smoothness. Due to its high price and exceptionally good properties, genuine leather is mainly used in more expensive cars in which the customer wants to have special and original interior [2]

\section{Properties of natural leather}

Animal skin processing belongs to the oldest human activities. The notes on the Babylonian clay tablets dating from $1250 \mathrm{BC}$ confirm this. Humankind has been using animal skin since ancient times for protection against external influences, attacks of other humans and animals, Fig. 2. [3, 4].

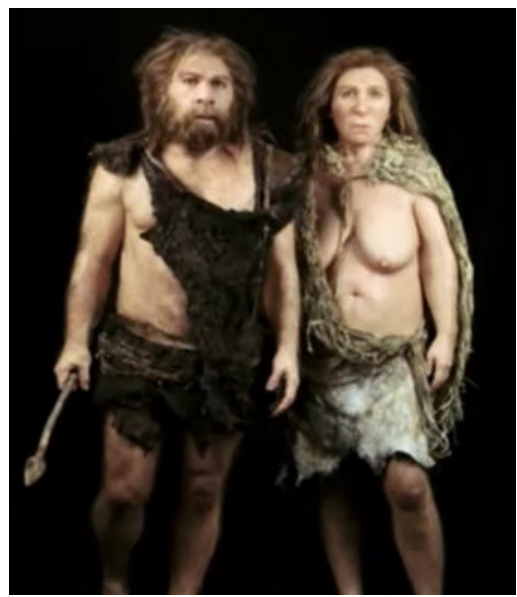

Figure 2. Neanderthal, Krapina [3]

Over time, the skin dried and became hard. It began to rot and decompose when exposed to moisture. The tanning process of animal skins gives them the necessary durability. The first tanning procedures were performed with animal brain mass and fats, as well as smoking. Today, the tanning process is carried out in rotating barrels for 10 to 12 hours. Tanning agents can be inorganic salts, such as chromium, aluminum, and zirconium or vegetable tanning agents, i.e. extracts of some tropical and subtropical plants. The use of tanning agents allows the crosslinking of collagen fibers, keeping the leather soft, elastic and stronger, more resistant to rotting and less water permeable, etc.

Leather is divided by origin into natural and artificial leather; according to the natural source, it can be bovine, calf, sheep, goat, pig, horse, alligator, snakeskin, etc.; according to the purpose, it can be classified as leather for footwear, clothing, fancy goods, automotive and aerospace industry, and for the furniture industry, etc. [4]. The appearance and quality of natural leather is influenced by the living conditions in which the animal was raised. Traces on the skin are caused by insect bites, wounds, scars, veins, wrinkles, brand marks, etc., Fig. 3. [5] 


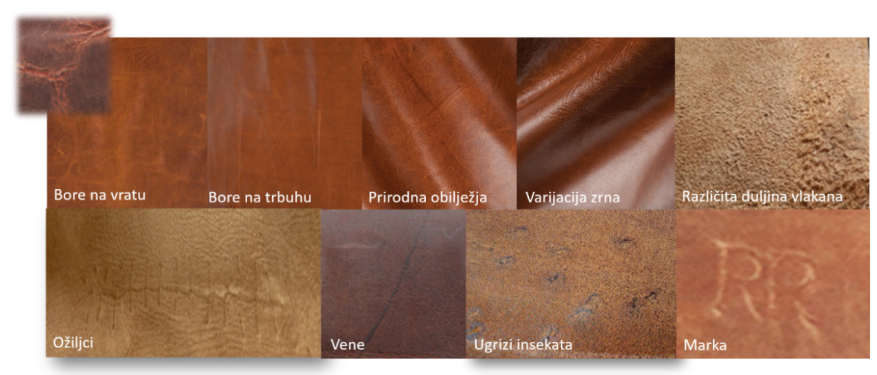

Properties of natural leather which are important in the automotive industry for car interior upholstery materials are abrasion resistance, mold resistance, resistance to long and cyclic stresses, elasticity, strength, shape stability, softness and comfort when in contact with the body, breathability, non-fraying selvages and easy care [1]. Table 1 gives the comparison of the properties of some materials used to make car upholstery [6].

Figure 3. Traces - natural characteristics on animal skin [5]

Table 1. Comparison of the materials used as car upholstery [6]

\begin{tabular}{|l|c|c|c|c|c|}
\hline & Water Resistance & Toughness & Soft Touch & Breathability & Mildew Resistant \\
\hline Leather & ++ & ++ & ++ & + & Yes \\
\hline Polycotton Drill & + & ++ & ++ & ++ & Yes \\
\hline Spancer Mesh & + & + & + & +++ & Yes \\
\hline Velour & + & + & +++ & + & Yes \\
\hline Neoprene (Neosupreme) & ++ & + & ++ & + & Yes \\
\hline Neoprene (Genuine) & +++ & ++ & ++ & + & Yes \\
\hline Leatherette & ++ & ++ & + & + & + \\
\hline Suede & + & + & ++ & Yes \\
\hline
\end{tabular}

+ Good; ++ Better; +++ Best

Table 1 reveals that natural leather in comparison to other materials shows very good properties. A great difference in properties is observable when compared to suede. The reason for this difference in properties lies in the fact that suede is made from lower layers of animal skin, which is softer but more sensitive to other influences.

\section{Natural leather car upholstery}

An example of good practice is Wollsdorf Leather, a company that specializes in the production of leather for the automotive, aerospace and furniture industry. It is the leader in tanning natural leather without chromium. The company uses high-quality bovine leather, originating mainly from the Central European region [7]. Ergonomically well-designed seats ensure optimal body posture, comfortable seating, a sense of safety and spaciousness during long driving hours. Material selection, precise cutting and high quality making up of car upholstery cutting parts by sewing should ensure the durability of the car upholstery for at least the duration of an average car lifecycle. Car upholstery should have dimensional stability, color fastness to sunlight, abrasion resistance and seam stability. One of the most important properties of car upholstery results from proper making up of its parts, which are often made of different materials with different properties, different raw materials of varying thicknesses, harnesses, etc. Car upholstery adaptation due to increasingly complex ergonomically adjusted seats requires a more serious structural approach that results in an increasing number of cutting parts to be joined. The number of stitches increases and greater importance is attached to seam quality. A contemporary piece of car upholstery contains an average of 15 cutting pieces sewn with a seam length of about $25 \mathrm{~m}$, whereas each car has an average of 120 pieces with a total seam length of about $175 \mathrm{~m}$. A variety of materials used for making car upholstery (natural leather, artificial leather, woven, knitted and non-woven fabrics) do not allow for thermal or any other making up technique other than sewing. The difference in thickness and components of textile laminates further complicates the joining of car upholstery cutting parts. The emergence of new, softer and more refined materials with lower thickness (napped fabrics with special chemical coatings, a combination of fabrics and non-woven textiles with special chemical and mechanical treatments, and various natural and artificial leathers with additional chemical treatments) favors high-quality seam joining of car upholstery cutting parts [1].

The disadvantages or problems that are present in the use of natural leather are related to the size of animal skin and animal lifecycle, as well as the natural features that developed on the animal skin in the course of life, Fig. 3. Natural leather is of different size and irregular shape. Leather quality control and defect marking are performed before cutting, Fig. 4 .

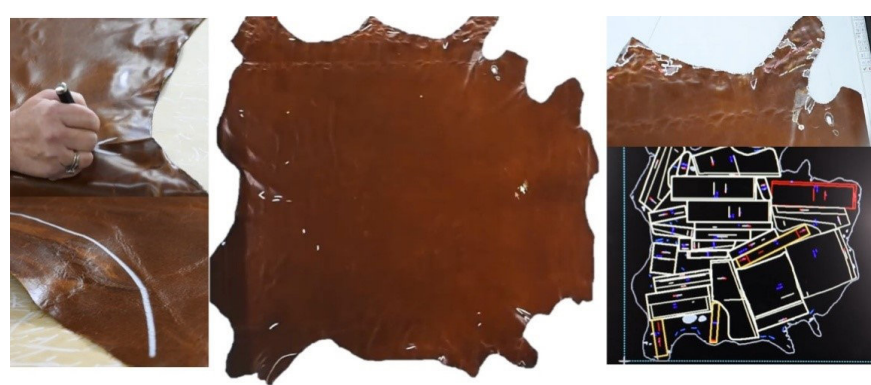

Figure 4. Leather defect marking and marker representation [8]

A marker is composed after marking defects on leather. Cutting requires extreme precision. If a damage on leather, e.g. from an insect bite is overlooked, it will later significantly shorten the lifecycle of car upholstery, Fig. 5. [8].

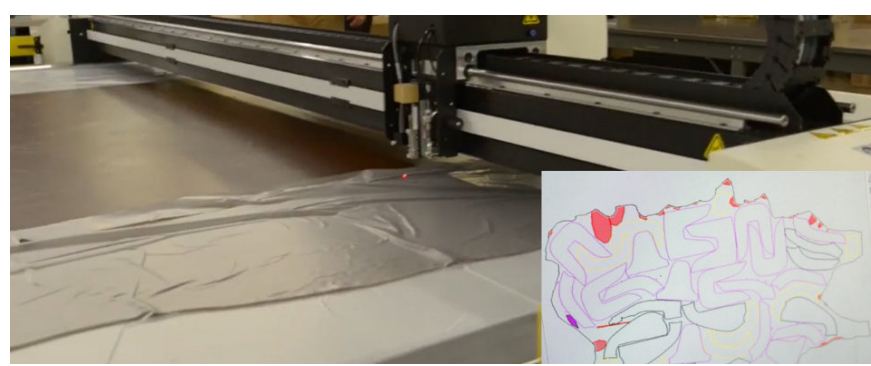

Figure 5. Leather cutting process (Gerber cutter) [9]

One of the shortcomings is the change of leather surface in quality, color and appearance. Therefore, it is very difficult to make car upholstery of uniform coloration and quality. From another point of view, this can be an advantage in the uniqueness that is appreciated on the market. Successive sorting of leather makes it possible to obtain the most appropriate leather shades that will give a special car upholstery design, but this requires an escalation of production prices, as well as more comprehensive knowledge of materials, patterns and colors currently available on the market.

\section{Making up process of car upholstery with a sewn seam}

In the manufacture of leather car upholstery, the most characteristic technological operations of sewing are performed on a universal sewing machine using double lockstitch type 301 [10]. According to the standard ISO 4916 , it is very important to choose the right type of 
sewing stitch. According to the standard, a sewn seam is a series of sewing stitches or a series of types of sewing stitches used on a single material layer or for joining multiple material layers [11]. Table 2 shows the most commonly used types of sewing stitches used to sew leather car upholstery.

Table 2. Types of sewing stitches and seams [10-13]

\begin{tabular}{|c|c|c|}
\hline Slika šava & $\begin{array}{c}\text { ISO } 4915 \\
\text { Tip šivaćeg uboda }\end{array}$ & $\begin{array}{c}\text { ISO 4916 } \\
\text { Tip šivaćeg šava }\end{array}$ \\
\hline & & $1.01 .01 / 301$ \\
\hline & & \\
\hline
\end{tabular}

According to the standard, needle threads are numbered $1,2,3$ etc., while bottom threads are denoted in lowercase a, b, c etc. [14]. Seam types are standardized according to the ISO 4916 standard [11]. Seam type consists of five digits. The first digit represents the seam class $(1-8)$, the second and third digits represent the arrangement of the sewing material layers $(01-99)$, the fourth and fifth digits represent the position of the stitch or needle penetration $(01-99)$ [14]. Figure 6 shows leather car upholstery and the interior of a BMW car in natural leather. The characteristic seam types are highlighted [15-18].
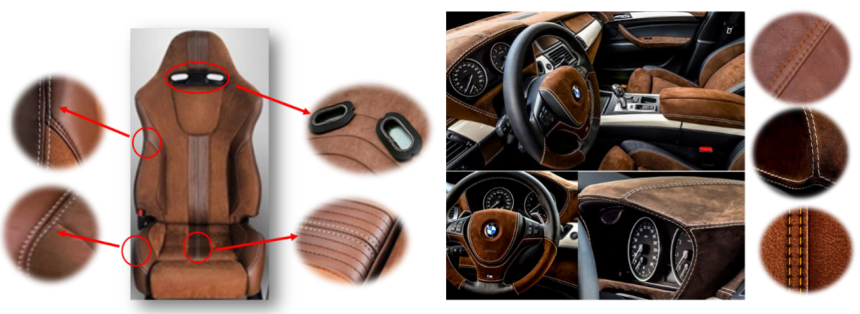

Figure 6. Leather car seat and interior of a BMW luxury car covered with natural leather [15-18]

Sewing car upholstery requires more robust sewing machines adapted to sewing thicker and multi-layered materials. The sewing machine should be able to sew materials of different raw material content and thicknesses without damaging the needle, thread and material. An example of a car upholstery sewing machine produced by Dürkopp Adler is shown in Fig. 7. Its optimal sewing speed amounts to about $2800 \mathrm{~min}^{-1}$. These machines can be made with extended head and free arm to facilitate the handling of a larger surface material during sewing.

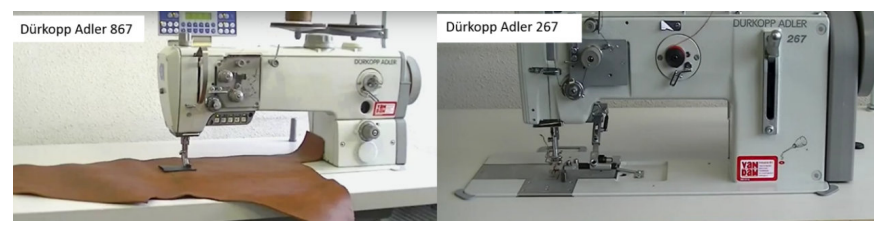

Figure 7. Dürkopp Adler sewing machines for sewing leather car upholstery [19]

The double presser foot is most commonly used for sewing leather-upholstered car seats. It consists of the external presser foot that holds the material and the internal presser foot that helps transport the material, Fig. 8.

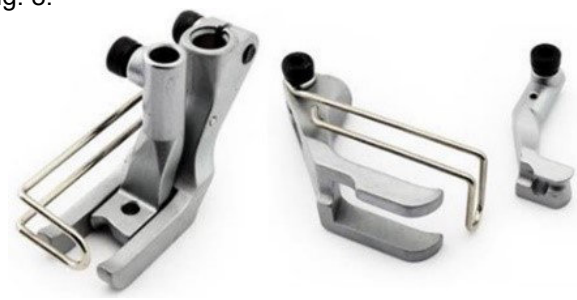

Figure 8. Dürkopp Adler double presser foot [20]
All the technological parameters of sewing that affect the seam quality should be harmonized, starting with the sewing material, sewing thread, sewing speed, material feed, machine equipment and needle type. Material, needle and sewing thread form a unique group that directly affects seam quality. Each segment of the upper thread passes 25 to 60 times through the needle eye until it comes into contact with the lower thread and is finally sewn into the material. Special attention should be paid to the sewing needle, namely to the needlepoint, surface treatment and the material that is on the surface of the needle. The needle should also have adequate hardness and good thermal conductivity to minimize damage to the material at the penetration site and to properly form a seam. Needles with cutting points for cutting leather are most commonly used for sewing leather car upholstery. This reduces friction and facilitates the passage of the thread through the leather. The cross section of the needlepoint is not round, but usually elliptical or triangular, Fig. 9. [1, 21].

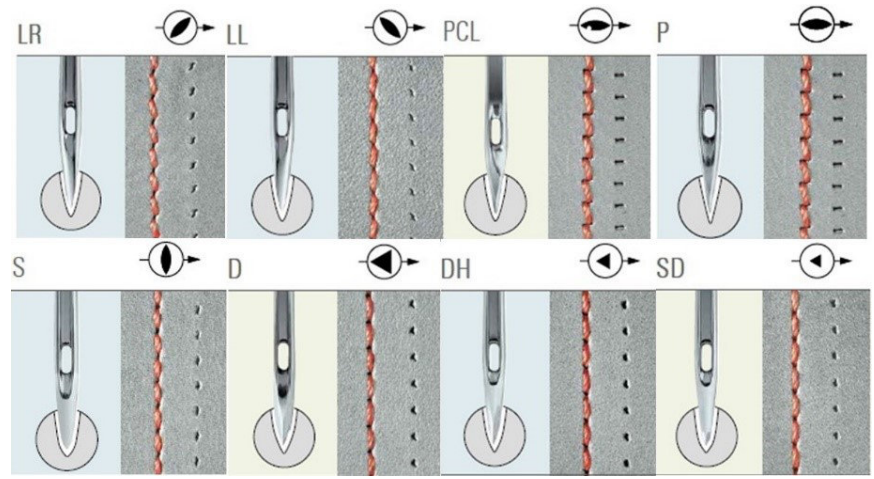

Figure 9. Needlepoint types of machine sewing needles for sewing leather [21]

The length and type of stitches, thread fineness and needle type are selected depending on the type and thickness of the material and the necessary seam strength. The properties of sewing thread for sewing car upholstery are usually the following: thread count: 50-105 tex, strength: 40$80 \mathrm{cN} /$ tex, elongation at break: $20-30 \%$, modulus of elasticity: $0.5-4 \mathrm{cN} / \mathrm{tex}$, raw material composition: polyester, polyamide [22].

\section{Conclusion}

The technological process of sewing leather car upholstery is a demanding and complex process. It is necessary to harmonize all the parameters in the technological sewing process in order to achieve a satisfactory seam quality. Defects when sewing leather are not tolerated, whether they occur as residual leather damage or sewing damage. Leather car upholstery and leather interior of the car represent luxury, requiring exceptional control before cutting, sewing and installing. Natural leather contains many residual features that cannot be eliminated, so they play an important role in assessing the quality and utilization of leather. They may represent defects to be avoided in cutting. However, some features that satisfy the required properties can provide originality and uniqueness of car upholstery materials. Moreover, they give the entire car interior a unique luxury appearance that is highly valued in the automotive industry.

\section{Literature}

1. https://www.olx.ua/obyavlenie/naturalnaya-kozha-kreyzi-horscrazyhorse-krs-IDB2HDd.html, Accessed:2019-09-22

2. Kovačević S., Ujević D.: Seams in car seat coverings: properties and performance, Joining Textiles, Chapter No.: 16, I. Jones, G.K. Stylios (ed.), Oxford, Cambridge, UK: Woodhead Publishing Ltd, 2013., 478506, DOI: 10.1533/9780857093967.4.478, ISBN: 078-1-84569-627-6.

3. https://edutorij.e-skole.hr/share/proxy/alfresconoauth/edutorij/api/proxy-guest/b52a40b8 3b f7-4d5c-bb1565a258050885/biologija-8/m01/j03/index.html, Accessed:2019-10-05

4. Mužic, M., Hitrec, P.: Preradba životinjske kože. Hrvatska enciklopedija. Sv. 6: Kn - Mak; Zagreb: Leksikografski zavod Miroslav Krleža, str. 216-216; ISBN 953-6036-36-3, 2004.

5. https://www.leathersatchel.com/guides/care-guide/natural-leather- 
markings/, Accessed:2019 -09-30

6. https://www.coverking.com/water-resistant-neoprene-seat-cover.html, Accessed: 2019-09-30

7. https://www.wollsdorf.com/w/hr/our_leather/production/, Accessed:2019-09-26

8. https://www.crlaine.com/media/ wysiwyg/cms/understanding-naturalleather/leather-bottom.jpg, Accessed:2019-09-29

9. https://www.boxmark.com/cutting_143.htm, Accessed:2019-09-26

10. ISO 4915:1991 Textiles - Stitch types - Classification and terminology

11. ISO 4916:1991 Textiles -- Seam types -- Classification and terminology

12. https://www.slideshare.net/umailsushant/stitch-type-threadconsumption, Accessed:2019-09-20

13. https://www.academia.edu/10367446/type_of_stitches, Accessed:2019-09-26

14. Rogale D. i sur.: Procesi proizvodnje odjeće, Zagreb, Tekstilnotehnološki fakultet, 2011.

15. https://www.pinterest.com/pin/ 292452569524253710/?nic=1, Accessed:2019-09-30

16. https://www.pinterest.com/pin/292452569524253735/, Accessed:2019-09-30

17. http://www.thehogring.com/2013/08/09/intersecting-2-french-seams/, Accessed:2019-09-30

18. https://www.crowworks.com/upholstery/flat-felled-seam-1/ Accessed:2019-09-30

19. https://www.youtube.com/watch?v=pjFsukk6mO4, Accessed:2019-0928

20. https://www.images-na.ssl-imagesamazon.com/images///31fd\%2BIXu-YL.jpg, Accessed:2019-09-28

21. https://leatherworker.net/forum/uploads/ monthly_2017_03/58cae0c134520_LeatherNeedlePointsG-

B.jpg.3ec6a76cf559cdcb9941135ebb7cdc97.jpg, Accessed: 2019-0930

22. Ujević, D. et al.: Impact of Joined Place on the Fabric Intended for Manufacturing Car Seat Covers", 2nd AUTEX Conference, Bruges, Belgium, 1-3 July, 2002. 